\title{
Analysis of the Energy Efficiency of District Heat Suppliers in Hungary Through Network Losses
}

\author{
Gábor Béla Süveges \\ Master Instructor, University of Miskolc \\ Beatrix Varga \\ Associate Professor, University of Miskolc
}

\begin{abstract}
Nowadays in Hungary, district heating is provided by 89 companies in 93 settlements, which supply more than 1.6 million people with heat. The sector is considered to be of national economic importance and it is therefore vital that this service is implemented effectively. A measure of efficiency is network loss, which value is on average between $12-13 \%$ in the sector. The aim of this study is to investigate whether there is a significant difference between the efficiencies of district heat suppliers. The empirical basis of the study is made up of the individual technical data of district heat suppliers from the years 2012-2017. The analysis was carried out with statistical methods that are suitable for exploring the relationships between qualitative and quantitative indicators. ${ }^{1}$
\end{abstract}

Keywords: Energy Efficiency, District Heat Suppliers, Hungary, Network Losses

\footnotetext{
${ }^{1}$ Acknowledgement: The described work was carried out as part of the "Sustainable Raw Material Management Thematic Network - RING 2017", EFOP-3.6.2-16-2017-00010 project in the framework of the Széchenyi 2020 Program. The realization of this project is supported by the European Union, cofinanced by the European Social Fund.
} 